\title{
RHIC abort kicker prefire report
}

\author{
Y. Tan, S. Perlstein
}

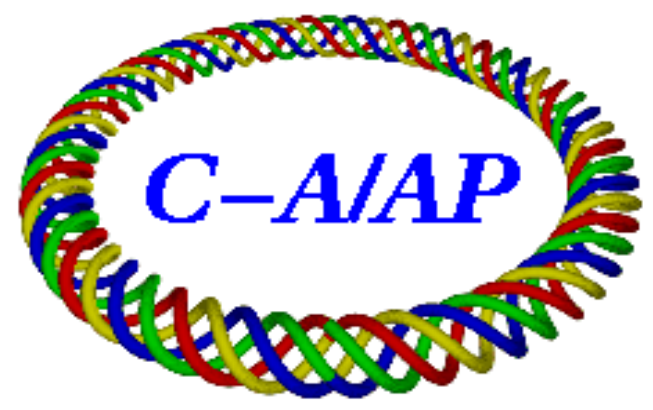

\section{Collider-Accelerator Department Brookhaven National Laboratory Upton, NY 11973}

Notice: This document has been authorized by employees of Brookhaven Science Associates, LLC under Contract No. DE-AC02-98CH10886 with the U.S. Department of Energy. The United States Government retains a nonexclusive, paid-up, irrevocable, world-wide license to publish or reproduce the published form of this document, or allow others to do so, for United States Government purposes. 


\title{
RHIC Abort Kicker Prefire Report
}

\author{
Y. Tan, S. Perlstein
}

Brookhaven National Laboratory, Upton, NY 11973, USA

In an attempt to discover any pattern to prefire events, abort prefire kicker data from 2007 to the present day have been recorded. With the 2014 operations concluding, this comprises 8 years of prefire data. Any activities that the Pulsed Power Group did to decrease prefire occurrences were recorded as well, but some information may be missing. The following information is a compilation of the research to date.

\section{Prefire overview}

For every run prefires occurred when the abort kicker power supplies were operated at $22 \mathrm{kV}$ or higher. The majority of the species were polarized protons $(\mathrm{PP})$ or gold $(\mathrm{Au})$. Other ions accelerated were copper $(\mathrm{Cu})$, uranium $(\mathrm{U})$, deuteron $(\mathrm{D})$ and helium $(\mathrm{He})$. Table 1 describes how prefires are related to the species being accelerated and the voltages used for each species.

\begin{tabular}{|c|c|c|c|c|c|c|}
\hline Run & $\begin{array}{l}\text { *Energy } \\
\text { GeV/nucleon }\end{array}$ & *Species & Days & $\begin{array}{l}\text { Abort Voltage } \\
\mathrm{kV}\end{array}$ & $\begin{array}{l}\text { Prefire } \\
\text { Yellow }\end{array}$ & $\begin{array}{l}\text { Prefire } \\
\text { Blue }\end{array}$ \\
\hline 2007 & 100 & $\mathrm{Au}-\mathrm{Au}$ & 128 & 27 & 12 & 18 \\
\hline 2008 & 100 & Au-D & 82 & $27 / 22$ & 2 & 3 \\
\hline 2009 & 250 & PP-PP & 60 & 27 & 1 & 9 \\
\hline 2010 & 100 & $\mathrm{Au}-\mathrm{Au}$ & 89 & 26 & 7 & 12 \\
\hline \multirow{2}{*}{2011} & 250 & PP-PP & 91 & 27 & 8 & 3 \\
\hline & 100 & $\mathrm{Au}-\mathrm{Au}$ & 49 & 27 & 5 & 4 \\
\hline \multirow{3}{*}{2012} & 255 & PP-PP & 37 & 27 & 1 & 0 \\
\hline & 96 & U-U & 28 & 26 & 2 & 0 \\
\hline & 100 & $\mathrm{Au}-\mathrm{Cu}$ & 43 & $26 / 22.8$ & 5 & 1 \\
\hline 2013 & 255 & PP-PP & 116 & 27 & 13 & 8 \\
\hline \multirow{2}{*}{2014} & 100 & $\mathrm{Au}-\mathrm{Au}$ & 96 & 26 & 12 & 6 \\
\hline & 100 & $\mathrm{Au}-\mathrm{He}$ & 22 & 26/27(three modules) & 2 & 0 \\
\hline
\end{tabular}

*Operation data are from http://www.agsrhichome.bnl.gov/RHIC/Runs/index.html.

Low energy modes are not listed in Table 1 because we never had a prefire while in those modes, except for one in 2009 at $11 \mathrm{kV}$ caused by a failed redundant trigger module. Chart 1 shows the total number of prefires experienced in the entire 8 year period and the numbers of prefires occurring in each run.
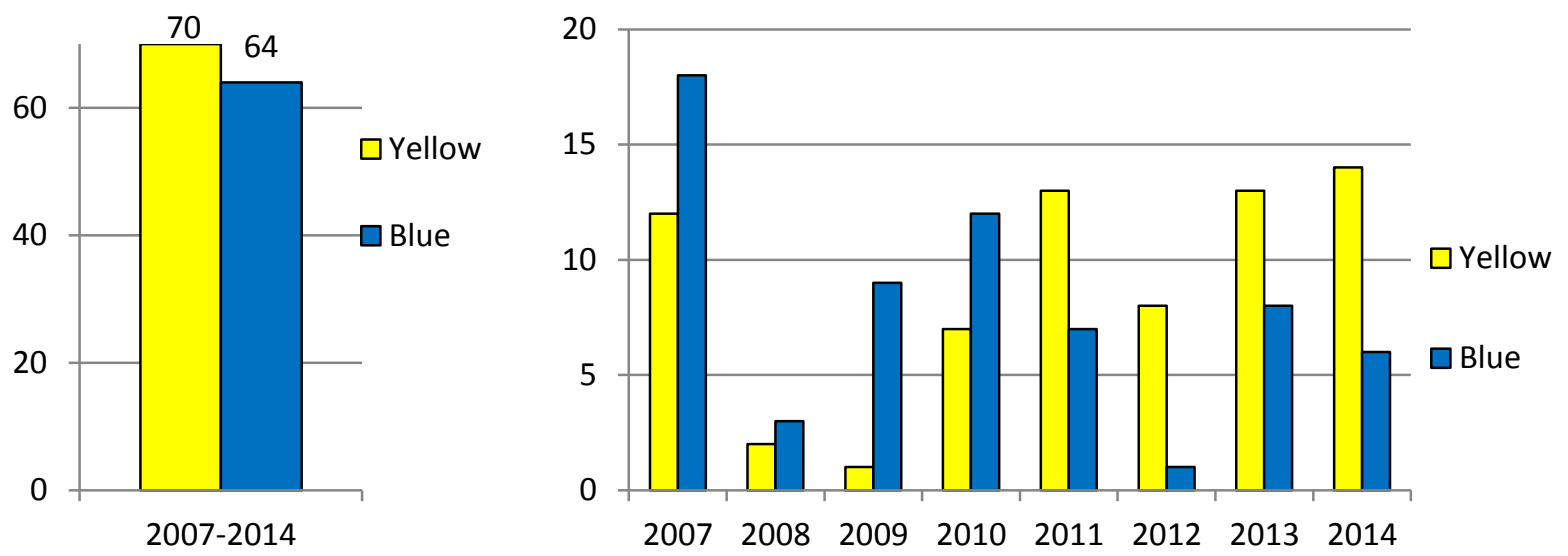
In terms of total prefires occurring during the period of this study, yellow and blue are very close.

Over the years, prefires of the blue abort kickers seem to decrease while those of the yellow do not.

From 2007 to 2010, yellow had less prefires than blue for each run. Starting in 2011, yellow experienced more prefires than blue.

2007 had the most prefires, a total of 30. But during 2008, the next run, there were only 5.

What did we do during that shutdown? In blue PFN \#2 and \#4 modules (which had 7 prefires each), the $\mathrm{CX} 3575 \mathrm{C}$ thyratron, the $5 \mathrm{uF} / 40 \mathrm{kV}$ capacitor, and eight $0.39 \mathrm{uF} / 45 \mathrm{kV}$ capacitors were replaced. Interestingly in yellow the prefires dropped down from 12 to 2 without any components being changed except the $5 \mathrm{uF} / 40 \mathrm{kV}$ capacitor in blue \#2 in the middle of the run.

\section{Prefire and species}

Table 2 below explores the relationship between prefires, species and length of the runs. There were 23 and 20 prefires for yellow and blue respectively with PP in 304 days; and 47 and 44 prefires with ions other than PP in 537 days. On average there was a prefire every 7.1 days for PP and 5.9 days for other species.

Table 2 Species and Prefires

(a)Prefires for PP

\begin{tabular}{|l|l|l|l|l|l|}
\hline Run & $\begin{array}{l}\text { Energy } \\
\text { GeV/nucleon }\end{array}$ & Species & Days & $\begin{array}{l}\text { Prefire } \\
\text { Yellow }\end{array}$ & $\begin{array}{l}\text { Prefire } \\
\text { Blue }\end{array}$ \\
\hline 2009 & 250 & PP-PP & 60 & 1 & 9 \\
\hline 2011 & 250 & PP-PP & 91 & 8 & 3 \\
\hline 2012 & 255 & PP-PP & 37 & 1 & 0 \\
\hline 2013 & 255 & PP-PP & 116 & 13 & 8 \\
\hline Total & & & 304 & 23 & 20 \\
\hline
\end{tabular}

(b) Prefires for ions other than PP

\begin{tabular}{|l|l|l|l|l|l|}
\hline Run & $\begin{array}{l}\text { Energy } \\
\text { GeV/nucleon }\end{array}$ & Species & Days & $\begin{array}{l}\text { Prefire } \\
\text { Yellow }\end{array}$ & $\begin{array}{l}\text { Prefire } \\
\text { Blue }\end{array}$ \\
\hline 2007 & 100 & Au-Au & 128 & 12 & 18 \\
\hline 2008 & 100 & Au-D & 82 & 2 & 3 \\
\hline 2010 & 100 & $\mathrm{Au}-\mathrm{Au}$ & 89 & 7 & 12 \\
\hline 2011 & 100 & $\mathrm{Au}-\mathrm{Au}$ & 49 & 5 & 4 \\
\hline \multirow{2}{*}{2012} & 96 & $\mathrm{U}-\mathrm{U}$ & 28 & 2 & 0 \\
\cline { 2 - 6 } & 100 & $\mathrm{Au}-\mathrm{Cu}$ & 43 & 5 & 1 \\
\hline \multirow{2}{*}{2014} & 100 & $\mathrm{Au}-\mathrm{Au}$ & 96 & 12 & 6 \\
\cline { 2 - 6 } & 100 & $\mathrm{Au}-\mathrm{He}$ & 22 & 2 & 0 \\
\hline Total & & & 537 & 47 & 44 \\
\hline
\end{tabular}

\section{Prefires and time of occurrence with relation to ramp and flat top}

A prefire may occur either during the charging voltage ramp or the charging voltage flat top. The ramp means the particles are being accelerated in the RHIC rings. A regular ramp takes about 4.5 minutes. The flat top means the acceleration process is completed and the beams are circulating in the RHIC rings. A normal flat top lasts 8 to 10 hours. The ramp and the flat top are shown in Figure 1. 


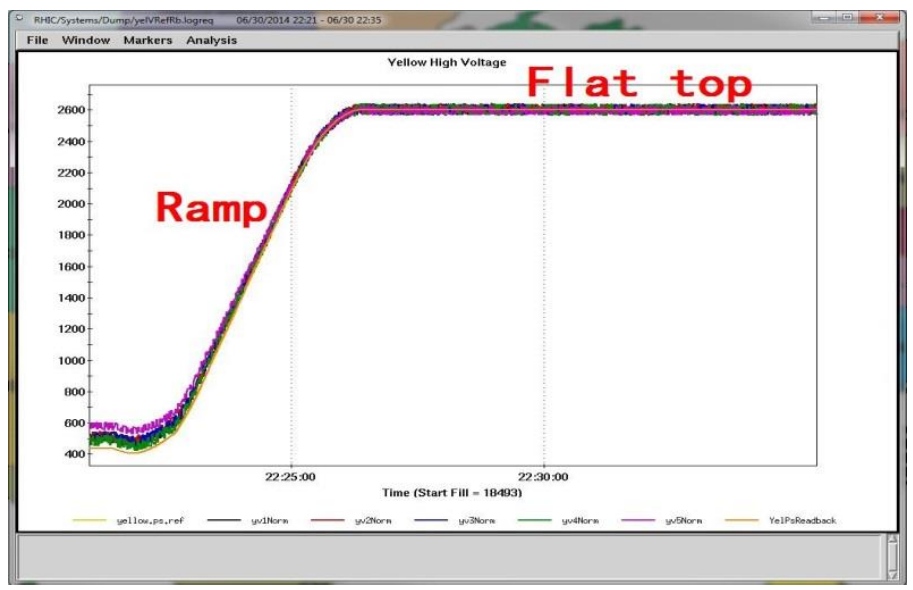

Figure 1 Abort kicker charging voltage ramp and flat top of a run

Table 3 explores prefires with relation to the ramp and flat top.

Table 3 Time of prefire occurrence

\begin{tabular}{|l|l|l|}
\hline Time of Prefire & Yellow & Blue \\
\hline Ramp & 22 & 22 \\
\hline Flat top <5 minutes & 15 & 11 \\
\hline Flat top 5-30 minutes & 10 & 12 \\
\hline Flat top $>30$ minutes & 23 & 19 \\
\hline Total & 70 & 64 \\
\hline
\end{tabular}

Chart 2 is a graphic representation of Table 3.
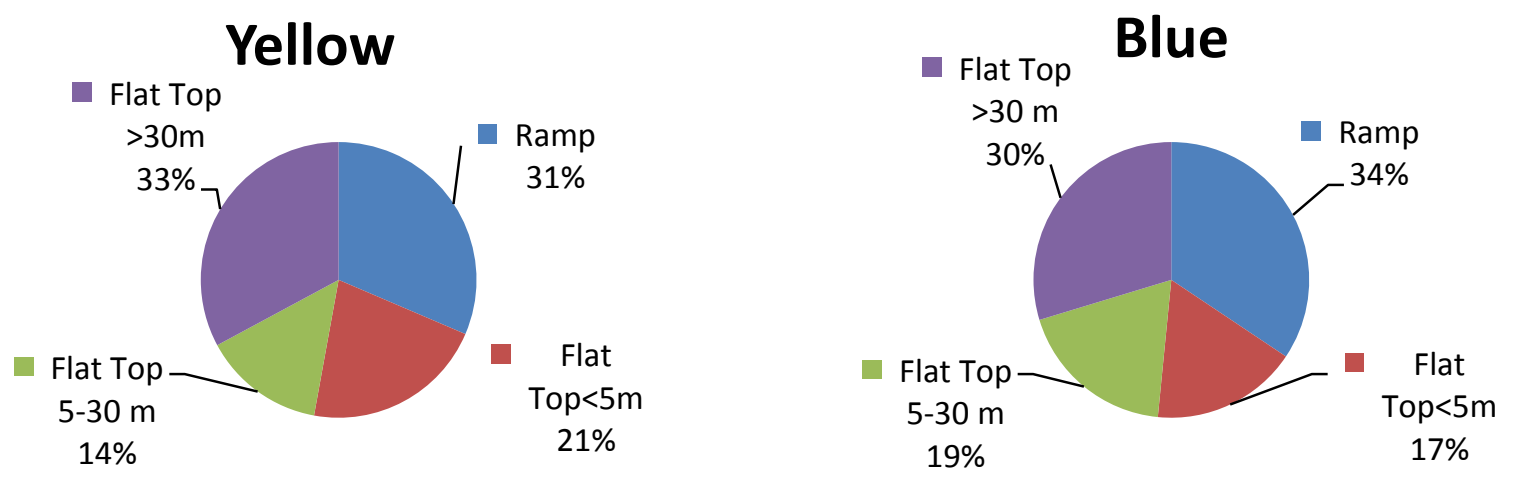

Chart 2 Yellow and Blue Prefire Time of Occurrence

For both yellow and blue, about $1 / 3$ of all prefires occurred during the ramp, and another $1 / 3$ of all prefires occurred more than 30 minutes in to the flat top. The prefires occurring during the ramp and during the first 5 minutes of the flat top represent about $50 \%$ of the total. We believe that this statistic is 
worth investigating because $50 \%$ of all prefire events occurring during the first 10 minutes of a run that can last 8-10 hours is a relatively significant number.

\section{Prefires by module position}

Table 4 enumerates the number of prefires vs. the PFN location over time. For each individual kicker module, there is a unique pattern of prefires. Chart 3 is a graphic representation of total prefires listed in Table 4.

Table 4 Prefires for each module

\begin{tabular}{|l|l|l|l|l|l|l|l|l|l|l|}
\hline & Y1 & Y2 & Y3 & Y4 & Y5 & B1 & B2 & B3 & B4 & B5 \\
\hline 2007 & 0 & 1 & 3 & 1 & 7 & 1 & 7 & 1 & 7 & 2 \\
\hline 2008 & 0 & 1 & 1 & 0 & 0 & 0 & 0 & 0 & 2 & 1 \\
\hline 2009 & 0 & 0 & 0 & 1 & 0 & 2 & 0 & 1 & 5 & 1 \\
\hline 2010 & 1 & 5 & 1 & 0 & 0 & 4 & 4 & 0 & 1 & 3 \\
\hline 2011 & 0 & 2 & 1 & 2 & 8 & 3 & 1 & 0 & 2 & 1 \\
\hline 2012 & 1 & 1 & 0 & 2 & 4 & 0 & 1 & 0 & 0 & 0 \\
\hline 2013 & 1 & 3 & 2 & 6 & 1 & 3 & 2 & 0 & 0 & 3 \\
\hline 2014 & 0 & 7 & 1 & 3 & 3 & 0 & 0 & 0 & 4 & 2 \\
\hline Total & 3 & 20 & 9 & 15 & 23 & 13 & 15 & 2 & 21 & 13 \\
\hline
\end{tabular}

\section{Yellow}

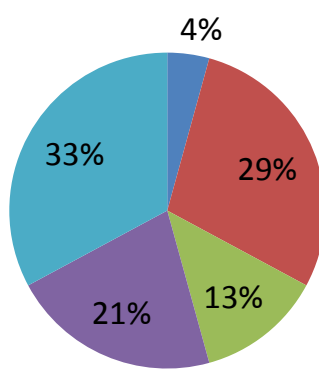

Blue

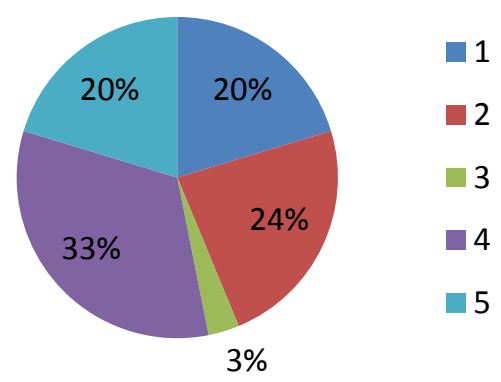

Chart 3 Percentage of total prefires in individual Yellow and blue modules

One module each in yellow and blue had very few prefires. Yellow \#1 and blue \#3 had only 3 and 2 prefires respectively in the last 8 years. The components in these two modules were seldom changed, while in other modules, such as yellow \#2, \#4, blue \#2, \#4, major components had been changed, and some components had been changed more than once.

\section{Prefire occurrence vs. average radiation}

A radiation survey was conducted in 2013. The results are shown in Table 5.

Table 5 Radiation survey results (unit: $\mathrm{mR} / \mathrm{Hr}$ )

\begin{tabular}{|l|l|l|l|l|l|l|l|l|l|l|}
\hline & Y1 & Y2 & Y3 & Y4 & Y5 & B1 & B2 & B3 & B4 & B5 \\
\hline 2013 & 0.9 & 0.4 & 0.1 & 0.5 & 0.5 & 2.4 & 1.0 & 0.23 & 0.05 & 0.05 \\
\hline
\end{tabular}

There does not appear to be a correlation between the radiation survey results and prefires. 


\section{What do we do when there is a prefire with no clearly discernible cause?}

We usually do one or both of two things before accessing the RHIC ring: (1) condition the modules, and (2) lower the thyratron reservoir voltages.

Are these procedures effective?

By checking the prefire history, we found that on occasion, during the conditioning or a few hours after the conditioning, there was another prefire. We also found that sometimes a few hours after reservoir voltages were decreased, there was a prefire. This is understandable, because there are several factors which may contribute to prefires, such as the thyratron self-firing, radiation triggering the thyratron, a loose connection, high voltage break-down, etc. Because of these factors, it is not clear whether performing the above mentioned two procedures is effective or not.

The same applies to our other procedures, such as replacing the thyratrons, replacing the $5 \mathrm{uF} / 40 \mathrm{kV}$ capacitors, replacing $0.39 \mathrm{uF} / 45 \mathrm{kV}$ capacitors, etc.

For now, for lack of better procedures, we recommend we continue to do what we have been doing.

\section{What is the solution to the prefires?}

As was mentioned before, there was not a single prefire at the voltage of $11 \mathrm{kV}$ or less except the one caused by a failed trigger module. One solution we can suggest is the installation of a higher voltage thyratron. The thyratrons currently in use are CX3575C, 60kV. A higher voltage rating thyratron, CX1193C, for example, is rated at $130 \mathrm{kV}$, and might resist prefiring. There are some concerns, however, such as the larger size may cause more prefires if radiation is the cause of prefires, or that thyratron may not be triggered at low injection voltage.

Jianlin Mi also had a solution. He suggests adding one more abort kicker module in each ring, thus reducing the $\mathrm{HV}$ by $1 / 6$ of $26 \mathrm{kV}$, i.e., $4.3 \mathrm{kV}$. But this would require significant changes in the RHIC ring.

\section{Summary}

From the previous data we may conclude that

(1) Abort kickers don't prefire at low energy modes (PFN voltages $<11 \mathrm{kV})$ except for component failure.

(2) Heavy ions appear to make the abort kickers more likely to prefire than polarized protons.

(3) About $50 \%$ of prefires occurred within the first 10 minutes of a run.

(4) One PFN module each in blue and yellow had very few prefires. This may be related to position in the beam line and is worthy of investigation. Perhaps we should consider swapping yellow PFN\#1 with PFN\#2, and blue PFN\#3 with PFN\#4.

References:

[1] RHIC run overview, http://www.agsrhichome.bnl.gov/RHIC/Runs/ . 
[2] Analysis of RHIC beam dump pre-fires, W Zhang, etc, 2011 Particle Accelerator Conference (PAC'11), http://www.bnl.gov/isd/documents/75266.pdf .

Attachments:

1. Abort Kicker area radiation survey in 2013. 
BNL RADIOLOGICAL SURVEY FORM

Bldg. \#: RHIC - Routine Location:1010 Kickers X Special Request Date/Time:2-25-13 1800 $\square$ RWP
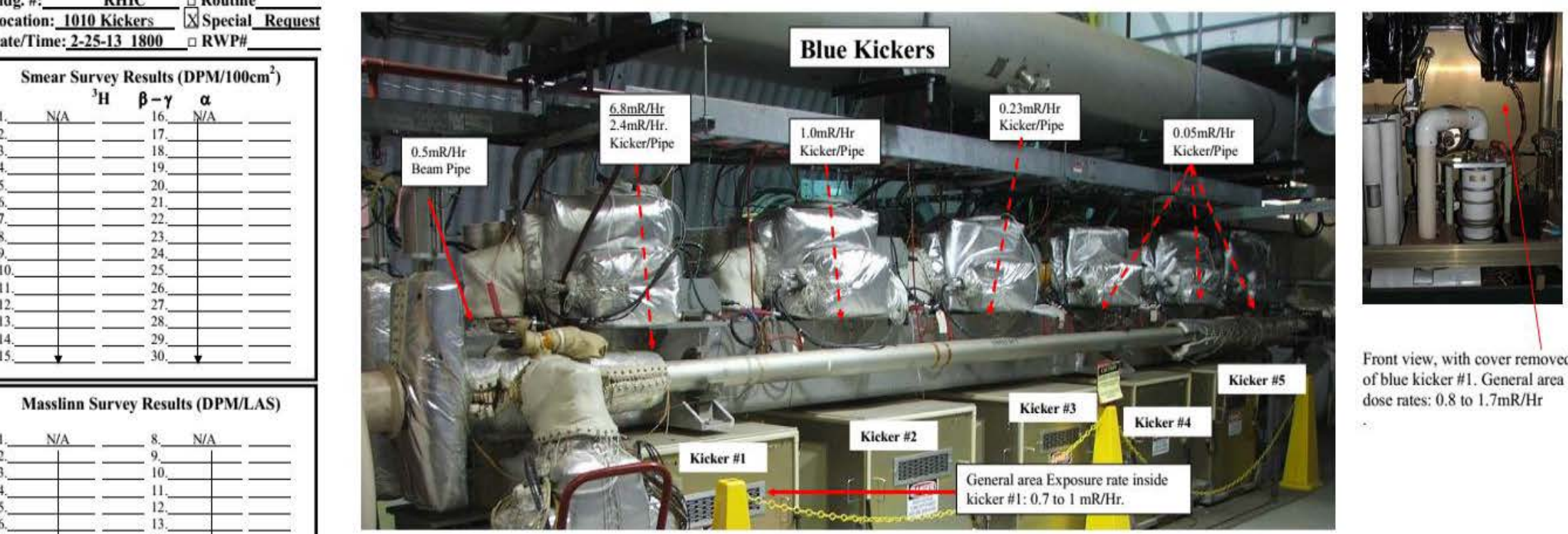

Masslinn Survey Results (DPM/LAS)

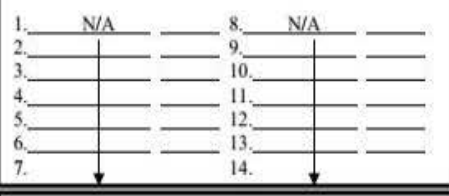

Legend: O Smear Location $\square$ Masslinn Location $\triangle$ Airborne

$\frac{x x y}{m z} \quad \begin{aligned} & x x x=\text { Contact Reading } \\ & z x=\text { Reading } Q 30 \mathrm{~cm} \\ & y=\text { Redation Type }\end{aligned}$

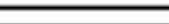

\begin{tabular}{|c|l|l|l|l|}
\hline \multicolumn{2}{|c|}{$\begin{array}{c}\text { Exposure Rates } \\
\text { (Highest) }\end{array}$} & \multicolumn{3}{|c|}{ Airbome Contamination } \\
\hline $\begin{array}{c}\text { Contact } \\
6.8 \mathrm{mR} / \mathrm{Hr} .\end{array}$ & Time & $\mu \mathrm{C} / \mathrm{ccc}$ & $\% \mathrm{DAC}$ \\
\hline $\begin{array}{c}\text { General } \\
\text { Area }\end{array}$ & $2.4 \mathrm{mR} / \mathrm{Hr}$. & $\mathrm{N} / \mathrm{A}$ & $\mathrm{N} / \mathrm{A}$ & $\mathrm{N} / \mathrm{A}$ \\
\hline \multicolumn{2}{|c|}{$\begin{array}{c}\text { aAll Exposure Rates are in } \mathrm{mR} / \mathrm{hr} \text { and taken at } 12 \\
\text { inches }(30 \mathrm{~cm}) \text { unless otherwise noted. }\end{array}$} \\
\hline
\end{tabular}

\begin{tabular}{|c|c|c|c|c|}
\hline Model & telepole & Model 19 & \multicolumn{2}{|c|}{ N/A } \\
\hline Serial \# & 093 & 291420 & & \\
\hline Cal Due Date & $8-3-13$ & $5-2-13$ & & \\
\hline $\begin{array}{c}\text { Source Checked } \\
\text { (Yes or No) }\end{array}$ & $y$ & $y$ & & \\
\hline
\end{tabular}

Form FS-1000.1

File Code FS72sk.09

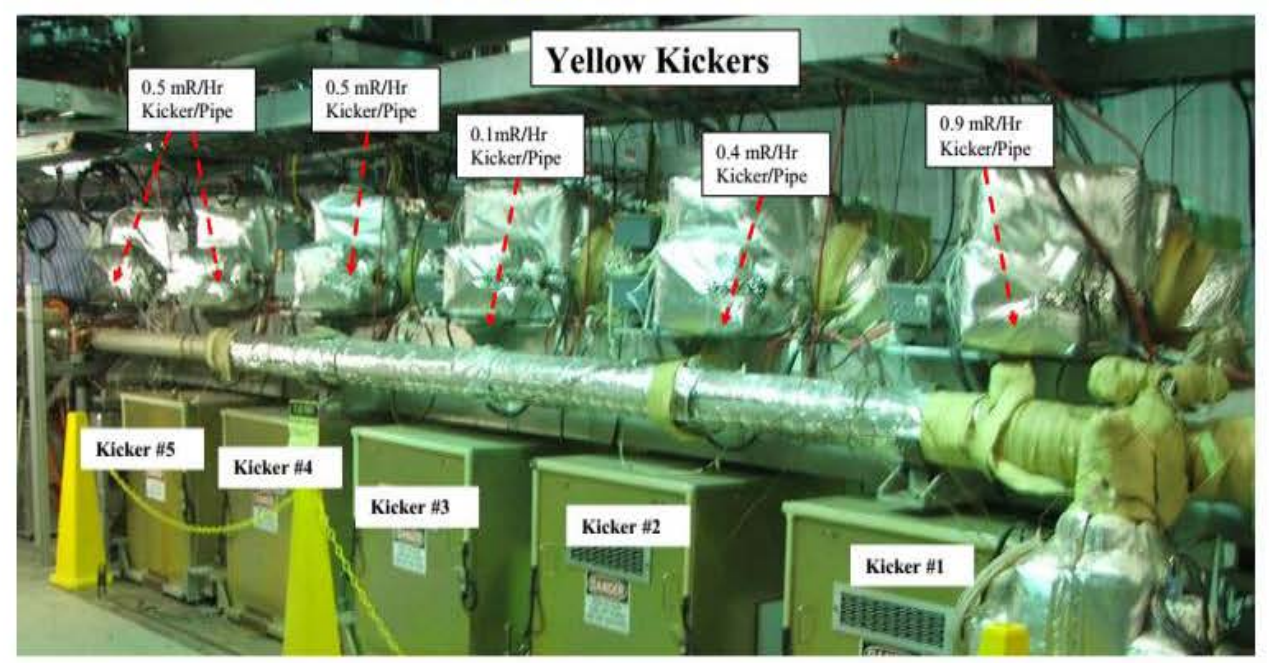

Exposure rates on capacitors removed irom blue kicker \#1

Saped capacito

Large square shaped capacitor: $24 \mu \mathrm{r} / \mathrm{Hr}$.

Surveyed By:__ Fintan Woods 2-25-13

Reviewed By Signature/Date

Signature/Date of blue kicker \#1. General area dose rates: 0.8 to $1.7 \mathrm{mR} / \mathrm{Hr}$ 